AperTO - Archivio Istituzionale Open Access dell'Università di Torino

\title{
An in-depth study on the agar gel effectiveness for built heritage cleaning
}

\section{This is a pre print version of the following article:}

Original Citation:

\section{Availability:}

This version is available http://hdl.handle.net/2318/1838960

since 2022-02-06T23:20:24Z

Published version:

DOI:10.1016/j.culher.2020.10.007

Terms of use:

Open Access

Anyone can freely access the full text of works made available as "Open Access". Works made available under a Creative Commons license can be used according to the terms and conditions of said license. Use of all other works requires consent of the right holder (author or publisher) if not exempted from copyright protection by the applicable law. 


\title{
AN IN-DEPTH STUDY ON THE AGAR GEL EFFECTIVENESS FOR BUILT HERITAGE CLEANING
}

Moira Bertasa $^{1}$, Carmen Canevali ${ }^{2 *}$, Antonio Sansonetti ${ }^{3}$, Massimo Lazzari ${ }^{4}$, Mary Malandrino $^{1}$, Roberto Simonutti ${ }^{2}$, Dominique Scalarone ${ }^{1}$

${ }^{1}$ Department of Chemistry, University of Turin, Via Pietro Giuria 7, Turin, Italy

${ }^{2}$ Department of Materials Science, University of Milano-Bicocca, Via Roberto Cozzi 55, Milan, Italy

${ }^{3}$ Institute for Conservation and Valorisation of Cultural Heritage (ICVBC), National Research Council (CNR), Via Roberto Cozzi 53, Milan, Italy

${ }^{4}$ Department of Physical Chemistry, Faculty of Chemistry, University of Santiago de Compostela, Santiago de Compostela, Spain

*corresponding author: carmen.canevali@unimib.it

\begin{abstract}
The effectiveness of Agar gels for copper stain removal from marble surfaces was systematically studied. Gels with different agar concentrations (1, 3, $5 \%)$ and additives (ethylenediaminetetraacetic acid, EDTA, and ammonium citrate tribasic, TAC), applied for different contact times (30 and $60 \mathrm{~min}$ ) on laboratory marble specimens, were tested. For better characterization, hydrogels were lyophilised and xerogels were obtained. Systematic comparison of different formulations was feasible on xerogels and performed in terms of: i) the morphological properties, by field-emission scanning electron microscopy (FE$\mathrm{SEM})$; ii) the type of $\mathrm{Cu}(\mathrm{II})$-complexes formed and their quantitative comparison by electron paramagnetic resonance (EPR) spectroscopy; iii) the total amount of copper removed from marble surfaces, by Inductively Coupled Plasma - Optical Emission Spectrometry (ICP-OES). Agar 1\% with TAC exhibited the highest effectiveness for copper stain removal after 60 min contact $\left(431 \mu \mathrm{g} / \mathrm{cm}^{2}\right.$ of copper mass removed per agar surface area). Such a good cleaning performance can be ascribed to the co-presence of three favourable properties: i) optimal gel concentration; ii) presence and iii) type of additive. In fact, it was observed that both the low gel concentration and the presence of TAC are
\end{abstract}


related to a narrow pore size distribution, besides the possibility of copper coordination. The presence of EDTA results in the collapse of the pores and in worse cleaning performances of gels, with respect to gels with TAC. Thus, a new method for studying gels was suggested, which allowed to suggest the best conditions for copper salt removal from built heritage.

KEYWORDS: agar gel, lyophilisation, cleaning effectiveness, copper, built heritage.

\section{INTRODUCTION}

Hydrogels are diffusely present in our life with many different applications, for instance in biology [1-3], food science [4,5], environmental remediation [6], biomedicine and pharmaceuticals [7]. Recently they have also gained an important role as a cleaning tool for cultural heritage conservation, since they are able to control water release [8-11]. In fact, many artistic materials are water sensitive because of solubility, swelling and decrease of mechanical properties when wet. In the field of conservation, several types of hydrogels can be used, from synthetic to natural polymers $[12,13]$. Among the latter ones, agar gels are a good option, since they are very versatile [14], have low impact on the artworks and low cost. Many types of agar powders are commercially available, each one characterized by particular properties and different cleaning performances [15]. Among them, AgarArt is currently the most used material by Italian restorers for removing metal stains from artwork surfaces [8,16-22]. Actually, the removal of green stains due to brochantite, $\mathrm{Cu}_{4}\left(\mathrm{SO}_{4}\right)(\mathrm{OH})_{6}$, is an important issue in cultural heritage conservation. Brochantite is a green-bluish compound present in the mixture of bronze corrosion products. It is partly washed away by rain from bronze elements and can stain marble surfaces located underneath.

Several research activities have recently been launched with the aim of understanding the cleaning mechanism of AgarArt and optimizing the effectiveness in metal stain removal. It was shown that the polysaccharide concentration strongly influences both the water state within the gel network [23] and the water release from gels to porous surfaces [15, 24]. Indeed, AgarArt $1 \% \mathrm{w} / \mathrm{v}$ releases far more water than gels $3 \%$ and $5 \% \mathrm{w} / \mathrm{v}$, acting as a "free water reservoir" [23].

The contact of gels, both pure and with additives, with marble laboratory specimens homogeneously stained with brochantite and cleaned in well-controlled and reproducible conditions allowed to study hydrogel mechanism and cleaning effectiveness [23]. In 
particular, it was shown that copper coordination, both by agar gels and by additives, is the cleaning driving force, and that stain removal was about twice more effective by using agar gels containing additives as ethylenediaminetetraacetic acid (EDTA) or ammonium citrate tribasic (TAC), than using pure gels [23]. Treatments by gels with additives brought back the laboratory specimen surfaces close to the colour features they had before artificial staining. The same effectiveness trend was observed during brochantite removal from the marble base of the bronze Napoleon statue by Antonio Canova, located in the Brera Gallery courtyard, Milan (Italy) [23]. Thus, the use of marble laboratory specimens allowed to compare the cleaning performance of agar hydrogels in different formulations (agar concentration and additive type). However, the relationship between gel morphological properties and performance could not be investigated, even if pore size distribution in agar gels was reported as a fundamental property in addressing both the water release and the copper salt removal from art surfaces by diffusion and/or osmosis mechanisms [25].

Thus, in order to systematically compare both the properties and the cleaning effectiveness of different AgarArt gel formulations, hydrogels were lyophilised (i.e. freeze-dried) immediately after contact with artificially brochantite-stained marble specimens. The obtained xerogels are representative of the morphology of the related hydrogels. In fact, fast freezing in liquid nitrogen leads to the formation of amorphous ice, which does not expand the hydrogel network unlike ice crystals. The subsequent controlled drying leads to the preservation of the native hydrogel morphology [26].

Thus, lyophilisation allows the systematic comparison of different gel formulations in terms of porosity, as determined by field emission-scanning electron microscopy (FESEM) [27]. These properties may influence the liquid phase release and the cleaning performances, but they are difficult to observe on hydrogels, even with an Environmental SEM (E-SEM) equipment. Moreover, after complete removal of water from hydrogels, the quantitative comparison among the $\mathrm{Cu}$ (II) centres present in the different gels was feasible by electron paramagnetic resonance (EPR) spectroscopy, besides the determination of the formed complexes. This result could improve the current knowledge about the extraction of copper by gels applied on stained surfaces. Finally, the concentration of copper dramatically increased in xerogels and the total amount of copper removed from marble specimens was accurately quantified by Inductively Coupled Plasma - Optical Emission Spectrometry (ICP-OES). 


\section{MATERIALS AND METHODS}

\subsection{Materials}

For laboratory specimen staining, $\mathrm{CuSO}_{4} \cdot 5 \mathrm{H}_{2} \mathrm{O}$ (Carlo Erba, Italy) and $\mathrm{Na}_{2} \mathrm{CO}_{3}$ (MerckMillipore, USA) were used.

AgarArt (CTS s.r.l., Italy), disodium EDTA (Merck-Millipore, USA) and TAC (Bresciani S.r.l., Italy) were used as raw materials and additives.

Agar Sigma (A7002, Sigma-Aldrich, USA) was used as reference.

Nitric acid (65 w \%, Merck Millipore, USA) was used for gel dissolution; mQwater@ was used as solvent.

\subsection{Preparation of laboratory specimens}

Specimens sized $5 \mathrm{~cm} \times 5 \mathrm{~cm} \times 2 \mathrm{~cm}$ of white statuary Carrara marble were used. Such a high quality marble assures the highest colour homogeneity after artificial staining. Nevertheless, being marble a natural material, some thin greyish veins were visible, due to silicate impurities in the former limestone. Thus, the most homogenous surface $(5 \mathrm{~cm} \times 5$ $\mathrm{cm}$ ) of each specimen was selected and polished with Struers RotoPol-11, using SiC paper at $180 \mu \mathrm{m}$ mesh. On this surface, green stains were obtained by in situ synthesis of brochantite, $\mathrm{Cu}_{4}\left(\mathrm{SO}_{4}\right)(\mathrm{OH})_{6}$, on the marble surface. For this purpose, marble specimens were immersed in solutions of $\mathrm{CuSO}_{4} \cdot 5 \mathrm{H}_{2} \mathrm{O} 0.05 \mathrm{M}$ in mQwater ${ }^{\circledR}$ at $55^{\circ} \mathrm{C}$, then solutions of $\mathrm{Na}_{2} \mathrm{CO}_{3} 0.05 \mathrm{M}$ were added dropwise, in excess with respect to the stoichiometric molar ratio $\mathrm{Cu}: \mathrm{OH}=2: 3$. After addition was complete, marble specimens remained immersed overnight into the reaction solution and were successively let dry in the air.

\subsection{Preparation, use and lyophilisation of agar gels}

Gels were prepared by dissolving the proper amount of powder in mQwater ${ }^{\circledR}(1,3$ and $5 \%$ w/v for AgarArt, $3 \%$ w/v for Agar Sigma), then the solution was heated in a microwave oven at $700 \mathrm{~W}$ for $2 \mathrm{~min}$ and cooled in the air. In the case of gels with additives, $1 \% \mathrm{w} / \mathrm{v}$ additives were added.

For the removal of copper stains, AgarArt gels and Agar Sigma gels, both pure and with additives, were applied in order to completely cover the most homogeneous surface of each specimen. Each hydrogel had size $5 \mathrm{~cm}$ x $5 \mathrm{~cm}$ x $0.5 \mathrm{~cm}$.

After different contact times (30 and $60 \mathrm{~min}$ ), small portions of the hydrogels $(5 \mathrm{~cm} \times 2.5$ $\mathrm{cm} \times 0.5 \mathrm{~cm}$ ) were immediately freezed in liquid nitrogen for $2 \mathrm{~min}$. Then lyophilisation 
was carried out for $32 \mathrm{~h}$ at 0.1 Torr and $233 \mathrm{~K}$ using a laboratory freeze-dryer Thermo Savant Modulyo-D. At the end, xerogels were obtained $(4.8 \mathrm{~cm} \times 2.3 \mathrm{~cm}$ x $0.3 \mathrm{~cm})$.

\subsection{Characterization}

\subsubsection{Field Emission-Scanning Electron Microscopy (FE-SEM)}

Small portions of xerogel were cut with a scalpel, fixed by a conductive adhesive on an aluminium support, then sputter-coated with a $10 \mathrm{~nm}$ iridium layer to facilitate high magnification observation. Microscopic examinations were carried out on a FE-SEM Zeiss Ultra Plus instrument, at an accelerating voltage of either 10 or $30 \mathrm{kV}$ at different magnifications in the range 30-100x and 300-1000x, respectively.

The average cross section areas of the xerogel pores were calculated using ImageJ [28], a public domain program designed for image processing. The distribution of the pore size has been reconstructed directly on FE-SEM images at a magnification of 100x, measuring the longest dimension of approximately 100 pores.

\subsubsection{Electron Paramagnetic Resonance (EPR) spectroscopy}

Xerogels were ground and inserted into quartz tubes having an internal diameter of $3 \mathrm{~mm}$. Then, EPR spectra were recorded at the X-band frequency on a Bruker EMX EPR spectrometer. Modulation frequency of $100 \mathrm{kHz}$, modulation amplitude of $16 \mathrm{G}$, microwave power of $5 \mathrm{~mW}$ and temperature of $298 \mathrm{~K}$ were used. The $g$ values were determined by standardization with diphenylpicrylhydrazyl (DPPH) and signal areas (a. u., $\pm 10 \%$ ) were calculated by double integration of the resonance lines. Care was taken to ensure that the sensitive part of the EPR cavity ( $1 \mathrm{~cm}$ length) was always full; no variations were observed in the apparent density of samples.

\subsubsection{Inductively Coupled Plasma-Optical Emission Spectroscopy (ICP-OES)}

Before ICP-OES analysis, xerogels were accurately weighed and dissolved in nitric acid, then solutions were brought to the same constant volume $(50 \mathrm{ml})$ with $\mathrm{mQwater} \circledast$. Total copper quantification $( \pm 10 \%)$ was performed by inductively coupled plasma-optical emission spectroscopy (ICP-OES) with a Perkin Elmer Optima 7000 DV apparatus, provided with an Echelle monochromator, a cyclonic spray chamber and a Teflon Mira Mist nebulizer. The instrumental conditions were: emission line $327.393 \mathrm{~nm}$; plasma power $1.3 \mathrm{~kW}$; sample aspiration rate $\sim 2 \mathrm{ml} / \mathrm{min}$; argon nebulizer flow $0.6 \mathrm{~L} / \mathrm{min}$; argon auxiliary flow $0.2 \mathrm{~L} / \mathrm{min}$ and argon plasma flow $15 \mathrm{~L} / \mathrm{min}$. 
Each concentration value was averaged on the basis of three measurements.

ICP-OES data were normalized according to each gel weight.

\section{RESULTS AND DISCUSSION}

The cleaning effectiveness of gels was studied in terms of agar concentration $(1,3,5 \%$ w/v), additive type (EDTA and TAC, both at $1 \% \mathrm{w} / \mathrm{v}$ ) and contact times (30 and $60 \mathrm{~min}$ ). The salt removal by Agar Sigma $3 \%$ w/v, both pure and with additives, was also studied as reference [29].

\subsection{FE-SEM characterization}

The morphological survey of the xerogel surface after copper stain removal from laboratory specimens was provided by FE-SEM. As it was verified that xerogel morphology does not change with contact time on marble specimens, only the images of samples after $60 \mathrm{~min}$ contact are discussed hereafter.

In pure gels, the FE-SEM images of cross-sections (Fig. 1 a-d) allowed to obtain histograms showing a narrow pore size distribution for AgarArt 1\% (Fig. 1 e-h). Specifically, the pore size range is 100-1000 $\mu \mathrm{m}$ for AgarArt 1\%, 0-1300 $\mu \mathrm{m}$ for AgarArt 3\% and 100-1400 $\mu \mathrm{m}$ for AgarArt 5\%. Agar Sigma $3 \%$ has pores in the range 0-1200 $\mu \mathrm{m}$. Moreover, the pore counts show for AgarArt $5 \%$ and for Agar Sigma $3 \%$ a very high predominance (30-35 counts) of pores between 100 and $300 \mu \mathrm{m}$, with respect to the other pure gels, which could be related to a higher gel surface area.

For $3 \%$ gels with additives, FE-SEM images are reported in Fig. 2 a-d and histograms with the pore size distribution are in Fig. 2 e-h. In AgarArt with EDTA (Fig. 2e), the pore size distribution is wider and shifts towards bigger pores (100-1500 $\mu \mathrm{m})$. Instead, AgarArt with TAC displays a narrow pore size distribution $(0-800 \mu \mathrm{m}$, Fig. 2f) with a very high predominance of pores between 100 and $400 \mu \mathrm{m}$ (30 counts). The same trend was observed for Agar Sigma, which displays pores in the range 100-1200 $\mu \mathrm{m}$ with EDTA and 0-700 $\mu \mathrm{m}$ with TAC, the latter with a high predominance of pores in the range 100-300 $\mu \mathrm{m}(40$ counts).

Thus, an important morphological difference between xerogels with EDTA and TAC was observed, both on AgarArt and on Agar Sigma. Such a difference is probably related to the structural collapse of the macroporous structure observed at high magnifications for 
AgarArt with EDTA (Fig. 3 a and b) and Agar Sigma with EDTA (Fig. 3 c and d), and not detected in all the other xerogels.

The structural collapse of the pore walls observed only in EDTA-gels is probably due to chemical and physical interactions between the additive molecules and the agar framework. Indeed, EDTA can interact with the active sites of the saccharide units of agar, modifying agar-water interactions, thus the pore surface in the xerogel. In addition, it is reasonable to assume that relatively large molecules, such as EDTA, are able to affect the polysaccharide chain conformation and to generate empty spaces in the double-helix structure responsible for gelling. This may result in a lower gel strength and in the structural collapse of the pores $[30,31]$.

\subsection{EPR characterization}

In order to compare the type of $\mathrm{Cu}(\mathrm{II})$-complexes formed in the different formulations, EPR spectra were recorded on xerogels after contact with the stained specimens and immediate lyophilisation. The study of xerogels allowed also the quantitative comparison among the paramagnetic species formed on the different gels, which was hindered for hydrogels.

For all samples, spectra appeared poorly resolved. Such a small resolution can be attributed both to the co-presence of several EPR active species and to the lyophilisation treatment. The EPR spectra after 30 min contact are reported in Fig. 4; the related signal parameters, intensities and the complex attributions are in Table 1. By prolonging the contact time from 30 to $60 \mathrm{~min}$, the parameters of EPR signals do not significantly change.

Pure Agarart $1 \%$ shows a weak axial EPR signal (Fig. 4a I), having values of g and A tensor components consistent with those of $\mathrm{Cu}(\mathrm{II})$ centres in a tetragonal symmetry field of oxygen atoms $(\mathrm{g} / /=2.31, \mathrm{~A} / /=156 \mathrm{G}, \mathrm{g} \perp \sim 2.1)[32]$. Thus, this signal can be attributed to magnetically diluted $\mathrm{Cu}$ (II) centres coordinated by agar gels, from now on termed as $\mathrm{Cu}$ agar complex.

For AgarArt $1 \%$ with EDTA, it was possible to observe the co-presence of two axial signals (Fig. 4a II): the same signal observed in pure agar gel (Cu-agar) and a second signal $(\mathrm{g} / /=2.27, \mathrm{~A} / /=166 \mathrm{G}, \mathrm{g} \perp \sim 2.1)$, which predominates and could be tentatively attributed to magnetically diluted $\mathrm{Cu}$ (II) centres coordinated by EDTA, from now on termed $\mathrm{Cu}$ EDTA complex. In addition, the presence of a broad isotropic signal at $\mathrm{g} \sim 2.1$, attributable to interacting $\mathrm{Cu}(\mathrm{II})$ centres, was observed.

Spectra of AgarArt $1 \%$ with TAC appeared particularly poorly resolved (Fig. 4a III). 
AgarArt $3 \%$ xerogels, both pure and with EDTA, show signals very similar to those observed for AgarArt $1 \%$ (Fig. 4b I, II). Instead, xerogel $3 \%$ with TAC shows the presence of an axial species $(\mathrm{g} / /=2.35, \mathrm{~A} / /=141 \mathrm{G}, \mathrm{g} \perp \sim 2.1)$, different from all the species so far observed, thus tentatively attributed to magnetically diluted $\mathrm{Cu}$ (II) centres coordinated by TAC, from now on termed as Cu-TAC complex (Fig. 4b III).

Pure AgarArt $5 \%$ displays a $\mathrm{Cu}$-agar signal more intense than the pure xerogels so far described (Fig. 4c I). For AgarArt $5 \%$ with EDTA (Fig. 4c II) the signal attributed to the $\mathrm{Cu}$-EDTA complex was absent and the signal of $\mathrm{Cu}$-agar predominates. The spectrum of AgarArt $5 \%$ with TAC (Fig. 4c III) shows the presence of a predominant Cu-TAC complex, in addition to the $\mathrm{Cu}$-agar complex.

Axial signals of $\mathrm{Cu}$-agar and $\mathrm{Cu}$-additives are observable both on hydrogels [23] and on xerogels. However, xerogels have slightly lower g// values and higher A// values than hydrogels obtained from the same formulation. These variations are in agreement with an increase in tetragonal distortion of the symmetry field [33], which could be due to the lyophilisation treatment.

Thus, EPR spectra of AgarArt gels show that by increasing agar concentration from 1 to 5 $\%$, an increase of $\mathrm{Cu}(\mathrm{II})$-agar and a decrease in $\mathrm{Cu}(\mathrm{II})$ centres coordinated by the additives are observed. In other terms, in AgarArt 1\% the formation of Cu-EDTA and Cu-TAC complexes is maximized, with respect to $3 \%$ and $5 \%$ gels.

For what concerns the relative intensities of the signals (Table 1), within each gel concentration, gels with EDTA contain the highest amounts of $\mathrm{Cu}$ (II) centres, followed by gels with TAC and, to a much lesser extent (at least 1-2 orders of magnitude), by pure gels. Moreover, AgarArt $1 \%$ with EDTA displays the absolute strongest EPR signal $\left(3 \times 10^{5}\right.$ a.u.), followed by AgarArt $1 \%$ with TAC ( $2 \times 10^{5}$ a.u.). This result confirms that gels with additives are more effective in coordinating copper than pure gels [23] and that in AgarArt $1 \%$ with additives the coordination of $\mathrm{Cu}$ (II) centres is maximized, with respect to the other gel concentrations. This is an important result, since it was reported that copper coordination is the driving force for stain removal from stones [23].

The removal of copper by Agar Sigma $3 \%$ w/v was also studied as a comparison. Pure Agar Sigma $3 \%$ showed a very weak unresolved EPR signal, which suggests that this gel cannot coordinate copper (Fig. 4d I). Agar Sigma $3 \%$ with EDTA (Fig. 4d II) and with TAC (Fig. 4d III) showed signals very similar to those observed for the corresponding AgarArt $3 \%$ gels with additives, however with lower intensities. These results show that Agar Sigma gives a lower copper coordination than AgarArt, probably due to the different 
chemical composition [15]. In particular, pyrolysis-GC/MS analyses showed for AgarArt peaks attributed to cellulose, probably due to an incomplete purification process, which left algal residues in the raw material. Instead, cellulose peaks are completely absent in the raw material purchased from Agar Sigma.

Table 1 -Parameters, relative intensities and attributionsof EPR signals observed at $298 \mathrm{~K}$ on agar xerogels after 30 min contact with laboratory-stained specimens.

\begin{tabular}{|c|c|c|c|c|c|c|}
\hline \multicolumn{2}{|l|}{ Sample } & \multirow{2}{*}{$\begin{array}{l}\mathrm{g} / / \\
\pm 0.01 \\
2.31\end{array}$} & \multirow{2}{*}{$\begin{array}{l}\text { A// } \\
\pm 5 \mathrm{G} \\
156\end{array}$} & \multirow{2}{*}{$\begin{array}{l}\mathrm{g} \perp \\
\pm 0.1 \\
2.1\end{array}$} & \multirow{2}{*}{$\begin{array}{l}\text { Signal } \\
\text { area (a.u.) } \\
\pm 10 \% \\
4 \times 10^{3}\end{array}$} & \multirow{2}{*}{$\begin{array}{l}\text { Signal attribution } \\
\text { Cu-agar }\end{array}$} \\
\hline \multirow{5}{*}{$\begin{array}{l}\text { AgarArt } \\
1 \%\end{array}$} & pure & & & & & \\
\hline & with & $"$ & $"$ & $"$ & \multirow[t]{3}{*}{$3 \times 10^{5}$} & $"$ \\
\hline & \multirow[t]{2}{*}{$\begin{array}{l}\text { EDTA } 1 \\
\%\end{array}$} & 2.27 & 166 & " & & $\begin{array}{l}\text { Cu-EDTA } \\
\text { (predominant) }\end{array}$ \\
\hline & & $\sim 2.1$ & n.d. & $"$ & & $\begin{array}{l}\text { Interacting } \mathrm{Cu} \text { (II) } \\
\text { centres }\end{array}$ \\
\hline & $\begin{array}{l}\text { with TAC } \\
1 \%\end{array}$ & n.d. & n.d. & $"$ & $2 \times 10^{5}$ & n. d. \\
\hline \multirow{5}{*}{$\begin{array}{l}\text { AgarArt } \\
3 \%\end{array}$} & pure & 2.31 & 156 & $"$ & $2 \times 10^{3}$ & $\mathrm{Cu}$-agar \\
\hline & with & $"$ & " & $"$ & \multirow[t]{3}{*}{$1 \times 10^{5}$} & $"$ \\
\hline & \multirow[t]{2}{*}{$\begin{array}{l}\text { EDTA } 1 \\
\%\end{array}$} & 2.27 & 166 & " & & $\begin{array}{l}\text { Cu-EDTA } \\
\text { (predominant) }\end{array}$ \\
\hline & & $\sim 2.1$ & n.d. & $"$ & & $\begin{array}{l}\text { Interacting } \mathrm{Cu} \text { (II) } \\
\text { centres }\end{array}$ \\
\hline & $\begin{array}{l}\text { with TAC } \\
1 \%\end{array}$ & 2.35 & 141 & $"$ & $9 \times 10^{4}$ & $\mathrm{Cu}-\mathrm{TAC}$ \\
\hline \multirow{4}{*}{$\begin{array}{l}\text { AgarArt } \\
5 \%\end{array}$} & pure & 2.31 & 156 & " & $8 \times 10^{3}$ & $\mathrm{Cu}$-agar \\
\hline & \multirow{2}{*}{$\begin{array}{l}\text { with } \\
\text { EDTA } 1 \\
\%\end{array}$} & $"$ & 156 & $"$ & $8 \times 10^{4}$ & $\begin{array}{l}\text { Cu-agar } \\
\text { (predominant) }\end{array}$ \\
\hline & & $\sim 2.1$ & n.d. & $"$ & & $\begin{array}{l}\text { Interacting } \mathrm{Cu} \text { (II) } \\
\text { centres }\end{array}$ \\
\hline & & 2.31 & 156 & " & $6 \times 10^{4}$ & Cu-agar \\
\hline
\end{tabular}




\begin{tabular}{|c|c|c|c|c|c|c|}
\hline & $\begin{array}{l}\text { with TAC } \\
1 \%\end{array}$ & 2.35 & 141 & $"$ & & $\begin{array}{l}\mathrm{Cu}-\mathrm{TAC} \\
\text { (predominant) }\end{array}$ \\
\hline \multirow{4}{*}{$\begin{array}{l}\text { Agar } \\
\text { Sigma } 3 \\
\%\end{array}$} & pure & n.d. & n.d. & " & n. d. & n. d. \\
\hline & \multirow{2}{*}{$\begin{array}{l}\text { with } \\
\text { EDTA } 1 \\
\%\end{array}$} & 2.27 & 166 & $"$ & \multirow[t]{2}{*}{$7 \times 10^{4}$} & $\begin{array}{l}\text { Cu-EDTA } \\
\text { (predominant) }\end{array}$ \\
\hline & & $\sim 2.1$ & n.d. & $"$ & & $\begin{array}{l}\text { Interacting } \mathrm{Cu} \quad \text { (II) } \\
\text { centres }\end{array}$ \\
\hline & $\begin{array}{l}\text { with TAC } \\
1 \%\end{array}$ & 2.35 & 141 & $"$ & $4 \times 10^{4}$ & $\mathrm{Cu}-\mathrm{TAC}$ \\
\hline
\end{tabular}

n.d. $=$ not detected

\subsection{ICP-OES analysis}

Total copper removed by gels from the laboratory marble surfaces was quantified by ICPOES after 30 and 60 min of contact and subsequent lyophilisation treatment.

ICP-OES data were normalized according to each sample weight.

Agar gels as prepared showed the presence of a negligible amount of copper.

In general, all examined gels with TAC display the highest amounts of copper, followed by gels with EDTA and, to a much lesser extent, by pure gels (Fig. 5 a, b). The absolute highest amount of copper was found in AgarArt $1 \%$ with TAC after 60 min contact (431 $\mu \mathrm{g} / \mathrm{cm}^{2}$ of copper mass removed per agar surface area). These data are more precise and accurate than those reported for hydrogels [23], which showed the same copper uptake for agar gels $3 \%$ added with EDTA and with TAC, both on laboratory specimens and on the base of Napoleon statue by A. Canova.

The high cleaning performance of AgarArt $1 \%$ with TAC can be related to the co-presence of three favourable properties:

i) optimal gel concentration, which influences both the pore size distribution and the water release. In particular, AgarArt $1 \%$ has a narrow pore size distribution and behaves as a "free" water reservoir [23];

ii) the additive presence, which allows an efficient metal coordination. Actually, both agar and additives are able to coordinate copper centres, but added gels display higher cleaning effectiveness than pure gels. The $\mathrm{Cu}(\mathrm{II})$ coordination in the different gel formulations showed that in AgarArt $1 \%$ with additives the coordination of $\mathrm{Cu}$ (II) centres is maximized. This is an important result, since copper coordination is the driving force for stain removal from stones; 
iii) the additive type, which influences the gel morphology. All gels with TAC showed a very high removal performance, followed by gels with EDTA and by pure gels, these last having a poor removal ability. The presence of TAC is related to a narrow pore size distribution, with a very high predominance of relatively small pores (between 100 and 400 $\mu \mathrm{m})$.

The quantification of copper by ICP-OES analyses carried out on xerogels is not in agreement with EPR results, which show that gels with EDTA contain a higher amount of $\mathrm{Cu}(\mathrm{II})$ centres than gels with TAC. Such a disagreement could be due to the presence of copper both in an EPR-active and in an EPR-silent form. The non-paramagnetic $\mathrm{Cu}$ (II) centres in AgarArt with TAC could be related to the presence of a high amount of copper centre, which form clusters containing magnetically coupled non-paramagnetic metal centres.

The effectiveness in copper removal decreases with increasing agar concentration. For instance, after 60 min contact the amount of copper removed by gel with TAC is 431 $\mu \mathrm{g} / \mathrm{cm}^{2}$ by AgarArt $1 \%, 246 \mu \mathrm{g} / \mathrm{cm}^{2}$ by AgarArt $3 \%$ and $138 \mu \mathrm{g} / \mathrm{cm}^{2}$ by AgarArt $5 \%$. These data are in agreement with EPR results and confirm the higher effectiveness of AgarArt $1 \%$.

A significant increase of copper removal with time was observed, especially for AgarArt 1 $\%$ with TAC (47 \% increase from 30 to $60 \mathrm{~min}$ ). Such an increase is in disagreement with the EPR results and confirms that non-paramagnetic $\mathrm{Cu}(\mathrm{II})$ centres form when high amounts of metal are present.

AgarArt $3 \%$ removed slightly higher copper amounts than Agar Sigma $3 \%$ : after 60 min contact, copper removed by gel added with TAC was $246 \mu \mathrm{g} / \mathrm{cm}^{2}$ in the case of AgarArt (Fig. $5 \mathrm{a}$ ) and $224 \mu \mathrm{g} / \mathrm{cm}^{2}$ in the case of Agar Sigma (Fig. $5 \mathrm{~b}$ ). This result is in agreement with the higher copper coordination observed by EPR on AgarArt and can be reasonably attributed to the compositional differences between the two raw materials [15].

Thus TAC was the most effective additive for copper removal. This result highlights an important difference between the two most used additives for gels (EDTA and TAC), which was observed neither in ICP-OES data of hydrogels nor in chromatic parameters of marble, both laboratory specimens and real case as the base of the bronze Napoleon statue by Antonio Canova [23]. Thus, these results allow to suggest the best conditions for brochantite removal from marble surfaces. 


\section{CONCLUSIONS}

The present paper describes the use of lyophilisation for systematically studying agar gels, in order to identify the more effective formulation for the removal of brochantite stains from marble surfaces. Lyophilisation of hydrogels, performed immediately after contact with laboratory stained specimens, gave xerogels with the same morphology as the related hydrogels. For the first time, such a procedure was used to overcome the limitations intrinsic in the hydrogels investigations. Thanks to this technique, it was possible to observe that AgarArt 1\% with TAC was the most effective formulation for copper removal after 60 min contact $\left(431 \mu \mathrm{g} / \mathrm{cm}^{2}\right.$ of copper mass removed per agar surface area). Such a high cleaning performance can be related to the co-presence of three favourable properties: i) optimal gel concentration, which influences both the pore size distribution and the water release;

ii) additive presence, which allows an efficient metal coordination. In AgarArt $1 \%$ with additives the coordination of $\mathrm{Cu}$ (II) centres is maximized. This is an important result, since copper coordination is the driving force for stain removal from stones;

iii) additive type, which influences the gel morphology. The lower effectiveness of gels with EDTA with respect to gels with TAC can be related to a lower gel strength and to the structural collapse of the pores, due to chemical and physical interactions between the large EDTA molecules and the agar framework.

These results allow to suggest the best cleaning conditions for copper salt removal from built heritage.

\section{REFERENCES}

[1] Akter, M.L., Haque, R., Salam, M.A. Comparative evolution of chromogenic agar medium and conventional culture system for isolation and presumptive identification of uropathogens. Pak. J. Med. Sci. 30(5), 1033-1038 (2014). DOI: 10.12669/pjms.305.5243 [2] Manickam, K., Mechireddy, R.R., Seshadri, S. Characterization of biomechanical properties of agar-based tissue mimicking phantoms for ultrasound stiffness imaging techniques. J. Mech. Behav. Biomed. Mat. 35, 132-143 (2014). DOI: 10.1016/j.jmbbm.2014.03.017

[3] Pavlik, E.J. et al. The proliferation of human tumor cell lines in the presence of different agas, agarose and methyl-cellulose. In vitro. 19(7), 530-550 (1983). 
[4] Tsai, A.C., Elias, J., Kelley, J.J., Robson, J.R. Influence of Certain Dietary Fibers on Serum and Tissue Cholesterol Levels in Rats. J. Nutr. 106(1) , 118-123 (1976) DOI: 10.1093/jn/106.1.118.

[5] Clapp, M.J.L. and Bradbrook C. Growth and longevity of rats fed an agar-bound diet. Labor. Anim. 16(2),138-142 (1982).

[6] Plank, T.N., Skala, L.P., Davis, J.T. Supramolecular hydrogels for environmental remediation: G4-quartet gels that selectively absorb anionic dyes from water. Chem. Commun. 53, 6235-6238 (2017). DOI: 10.1039/C7CC03118A

[7] Albertus, J. Medicinal and pharmaceutical uses of seaweed natural products: A review. J. Appl. Phycol. 16(4), 245-262 (2004).

DOI: https://doi.org/10.1023/B:JAPH.0000047783.36600.ef

[8] Angelova, L.V., Ormsby, B., Townsend, J.H., Wolbers, R. Gels in Conservation. Archetype Publications (London, 2017).

[9] Bonelli, N., Montis, C., Mirabile, A., Berti, D., Baglioni, P. Restoration of paper artworks with microemulsions confined in hydrogels for safe and efficient removal of adhesive tapes. PNAS U.S.A. 115(23), 5932-5937 (2018). DOI: https://doi.org/10.1073/pnas.1801962115

[10] Baglioni, M. et al. Complex Fluids Confined into Semi-interpenetrated Chemical Hydrogels for the Cleaning of Classic Art: A Rheological and SAXS Study. ACS Appl. Mater. Interfaces. 10(22), 19162-19172 (2018). DOI: 10.1021/acsami.8b0184 [11] Angelova, L.V., Ormsby, B., Richardson, E. Diffusion of water from a range of conservation treatment gels into paint films studied by unilateral NMR: Part I: Acrylic emulsion paint. Microchem. J. 124, 311-320 (2016).

DOI: https://doi.org/10.1016/j.microc.2015.09.012

[12] Carretti, E. et al. New Frontiers in Materials Science for Art Conservation: Responsive Gels and Beyond. Acc. Chem. Res. 43(6), 751-760 (2010). DOI: 10.1021/ar900282h [13] Bonelli, N., Poggi, G., Chelazzi, D., Giorgi, R., Baglioni, P. Poly (vinyl alcohol)/poly (vinyl pyrrolidone) hydrogels for the cleaning of art. J. Colloid Inter Sci. 536, 339-348 (2019). DOI: https://doi.org/10.1016/j.jcis.2018.10.025

[14] Sansonetti, A., Bertasa, M., Canevali, C., Rabbolini, A., Anzani, M., Scalarone, D. A Review in using agar gels for cleaning art surfaces, J. Cult. Herit. (2020). In press.

[15] Bertasa, M. et al. Cleaning materials: A multi-analytical characterization of commercial agar powders. J. Anal. Appl. Pyrol. 125, 310-1732 (2017). DOI: https://doi.org/10.1016/j.jaap.2017.03.011 
[16] Gullotta, D. et al. Setup of a sustainable indoor cleaning methodology for the sculpted stone surfaces of the Duomo of Milan. Herit. Sci. 2(6) (2014). DOI: https://doi.org/10.1186/2050-7445-2-6

[17] Mazzuca, C. et al. Gellan hydrogel as a powerful tool in paper cleaning process: A detailed study. J. Colloid Inter Sci. 416, 205-211 (2014). DOI:

https://doi.org/10.1016/j.jcis.2013.10.062

[18] Sansonetti, A. et al. A cleaning method based on the use of agar gels: new tests and perspectives. (Ed. G. Wheeler) 12th International Congress on the Deterioration and Conservation of Stone, (New York: ICOM-CC, 2014)

[19] Casoli, A. et al. Evaluation of the effect of cleaning on the morphological properties of ancient paper surface. Cellulose 20(4), 2027-2043 (2013). DOI: 10.1007/s10570-0139975

[20] Bertasa, M. et al. Soluble Salts Extraction with Different Thickeners: Monitoring of the Effects on Plaster. IOP Conf. Series: Materials Science and Engineering. 364, 012076 (2018). DOI:10.1088/1757-899X/364/1/012076

[21] Di Tullio, V. et al. ${ }^{1} \mathrm{H}$ NMR depth profiles combined with portable and microanalytical techniques for evaluating cleaning methods and identifying original, nonoriginal, and degraded materials of a 16th century Italian wall painting. Microchem. J. 141, 40-50 (2018). DOI: https://doi.org/10.1016/j.microc.2018.04.034

[22] Prati, S. et al. Sustainability in art conservation: a novel bio-based organogel for the cleaning of water sensitive works of art. Pure Appl. Chem. 90(2), 239-251 (2018). DOI: https://doi.org/10.1515/pac-2017-0507

[23] Canevali, C. et al. A multi-analytical approach for the study of copper stain removal by agar gels Microchem. J. 129, 249-258 (2016). DOI: 10.1016/j.microc.2016.07.007

[24] Bertasa, M., Poli, T., Riedo, C., Di Tullio, V., Capitani, D., Proietti, N., Canevali, C., Sansonetti, A. Scalarone, D. A study of non-bounded/bounded water and water mobility in different agar gels. Microchem. J. 139, 306-314 (2018). DOI: https://doi.org/10.1016/j.microc.2018.03.016

[25] Heritage, A., Heritage, A., Zezza, F. Desalination of historic building, stone and wall paintings, Archetype Publications (London, 2013).

[26] Paterson, S.M. et al. Laser scanning confocal microscopy versus scanning electron microscopy for characterization of polymer morphology: Sample preparation drastically distorts morphologies of poly(2-hydroxyethyl methacrylate)-based hydrogels. J. App. Polym. Sci. 127, 4296-4304 (2013). DOI: 10.1002/app.38034 
[27] Domingues, J., Bonelli, N., Giorgi, R., Fratini, E., Baglioni, P. Innovative method for the cleaning of watersensitive artifacts: synthesis and application of Highly retentive chemical hydrogels. Int. J. Conserv. Sci., Special Issue 4, 715-722 (2013).

[28] Rasband, W.S., ImageJ 1x (Version 1.50i), National Institutes of Health, USA (2012). [29] Pereira, L., Sousa, A., Coelho, H., Amado, A.M., Ribeiro-Claro, P.J.A. Use of FTIR, FT-Raman and 13C-NMR spectroscopy for identification of some seaweed phycocolloids. Biomol. Eng. 20, 223-228 (2003). DOI: https://doi.org/10.1016/S1389-0344(03)00058-3 [30] Mohammed, Z.H., Hember, M.W.N., Richardson, R.K., Morris, E.R. Kinetic and equilibrium processes in the formation and melting of agarose gels. Carbohyd. Polym. 36, 15-26 (1998). DOI: https://doi.org/10.1016/S0144-8617(98)00011-3

[31] Syed, K.H.G., Saphwarm, A, in Progress in Molecular and Environmental Bioengineering from Analysis and Modelling to Technology Applications (ed. A. Carpi) 117 - 150 (IntechOpen, London, 2011).

[32] Canevali, C., Morazzoni, F., Scotti, R., Cauzzi, D., Moggi, P., Predieri, G. Electron Paramagnetic Resonance Characterisation of Silica-Dispersed Copper Molybdate Obtained by Sol-Gel and Impregnation Methods. J. Mater. Chem. 9, 507-513 (1999). DOI: 10.1039/A806167J

[33] Bassetti, V., Burlamacchi, L., Martini, G. Use of paramagnetic probes for the study of liquid adsorbed on porous supports. Copper(II) in water solution. J. Am. Chem. Soc. 101(19), 5471-5477 (1979). DOI: 10.1021/ja00513a003

\section{ACKNOWLEDGMENTS}

Compagnia di San Paolo and University of Torino are gratefully acknowledged for funding Project Torino_call2014_L2_181 through "Bando per il finanziamento di progetti di ricerca di Ateneo - anno2014" (Project title: Polymer gels for cultural heritage).

ML acknowledges the support by Xunta de Galicia (Grupo con Potencial de Crecemento ED431B 2018/1, and Centro Singular de Investigación de Galicia accreditation 20162019, ED431G/09). MB also acknowledges MIUR, Italy, for financial support and the University of Santiago de Compostela where she undertook a pre-doctoral 2-months staying, realizing SEM characterization.

\section{AUTHOR CONTRIBUTIONS}


MB carried out the preparation of samples, the FE-SEM characterization and image analysis. CC carried out the EPR characterization, with interpretation, and gave the main contribution to the conception of the work. ML carried out the FE-SEM characterization, with interpretation. MM carried out the ICP-OES analysis and interpretation. RS contributed to the interpretation of the results. AS and DS made substantial contributions to the conception of the work, coordinating the contribution of all the authors. $\mathrm{CC}$ and $\mathrm{MB}$ wrote the paper in consultation with all the authors.

\section{COMPETING INTERESTS}

The authors declare no competing interests.

\section{FIGURE CAPTIONS}

Figure 1 - FE-SEM images at 100x magnifications and corresponding pore size distribution histograms of the following pure xerogels: AgarArt 1\% (a and e), AgarArt 3\% (b and f), AgarArt 5\% (c and g) and Agar Sigma 3\% (d and h).

Figure 2 - FE-SEM images at 100x magnifications and corresponding pore size distribution histograms of the following $3 \%$ xerogels: AgarArt with EDTA (a and e), AgarArt with TAC (b and f), Agar Sigma with EDTA (c and g) and Agar Sigma with TAC (d and $h$ ).

Figure 3 - FE-SEM images of AgarArt 1\% (a, b) and Agar Sigma 3\% (c, d), both added with EDTA. Magnifications are 500x (a), 1000x (b and d) and 100x (c).

Figure 4 - EPR spectra recorded at $298 \mathrm{~K}$ on AgarArt $1 \%$ (a), AgarArt $3 \%$ (b), AgarArt $5 \%$ (c) and Agar Sigma $3 \%$ (d) after 30 min contact with laboratory-stained specimens. Xerogels: pure (I), with EDTA (II), with TAC (III).

Figure 5 - ICP-OES data showing the total copper content per agar surface area of AgarArt (a) and Agar Sigma (b) after $30 \mathrm{~min}$ (solid) and $60 \mathrm{~min}$ (striped) contact with laboratorystained specimens. 

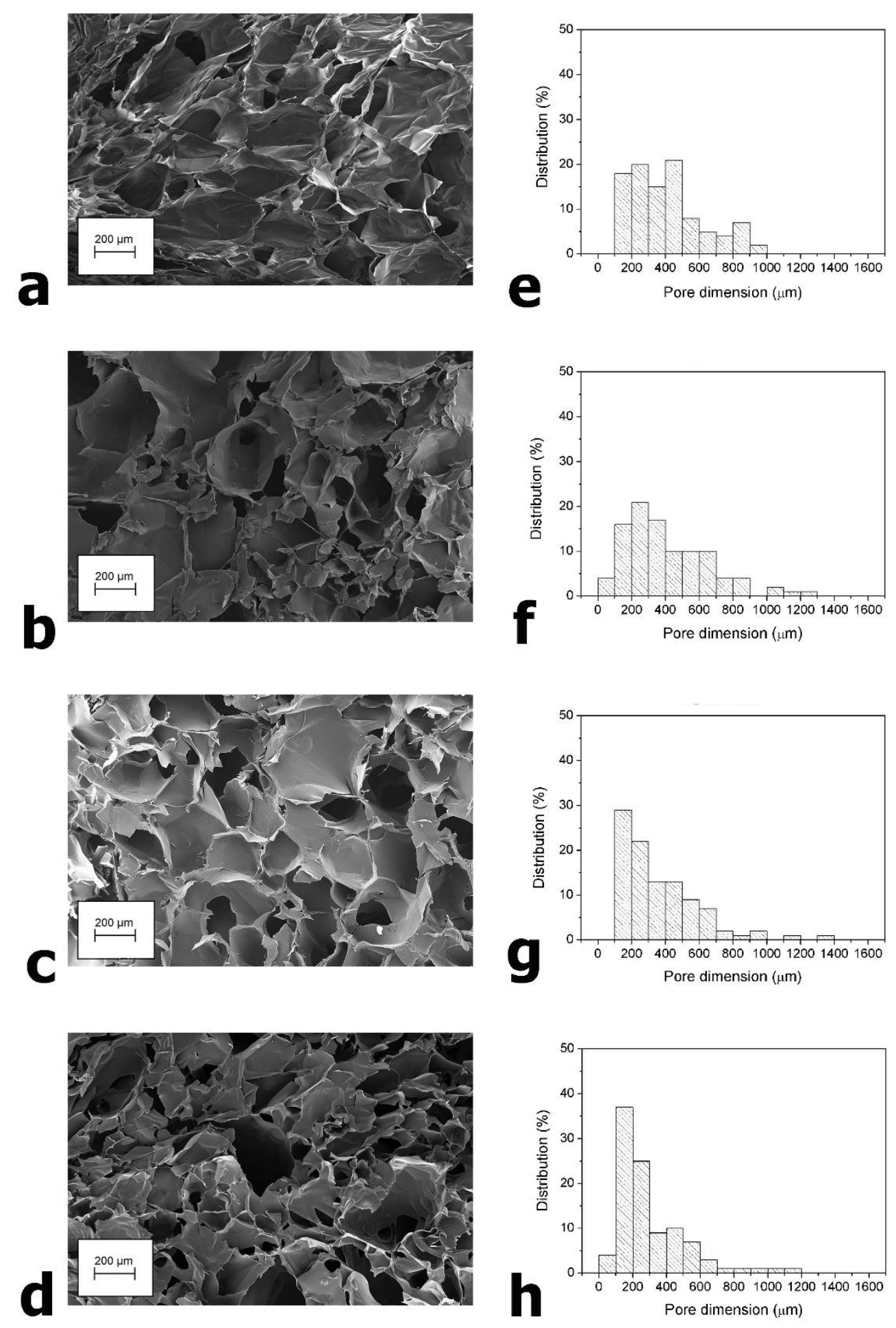

Figure 1 

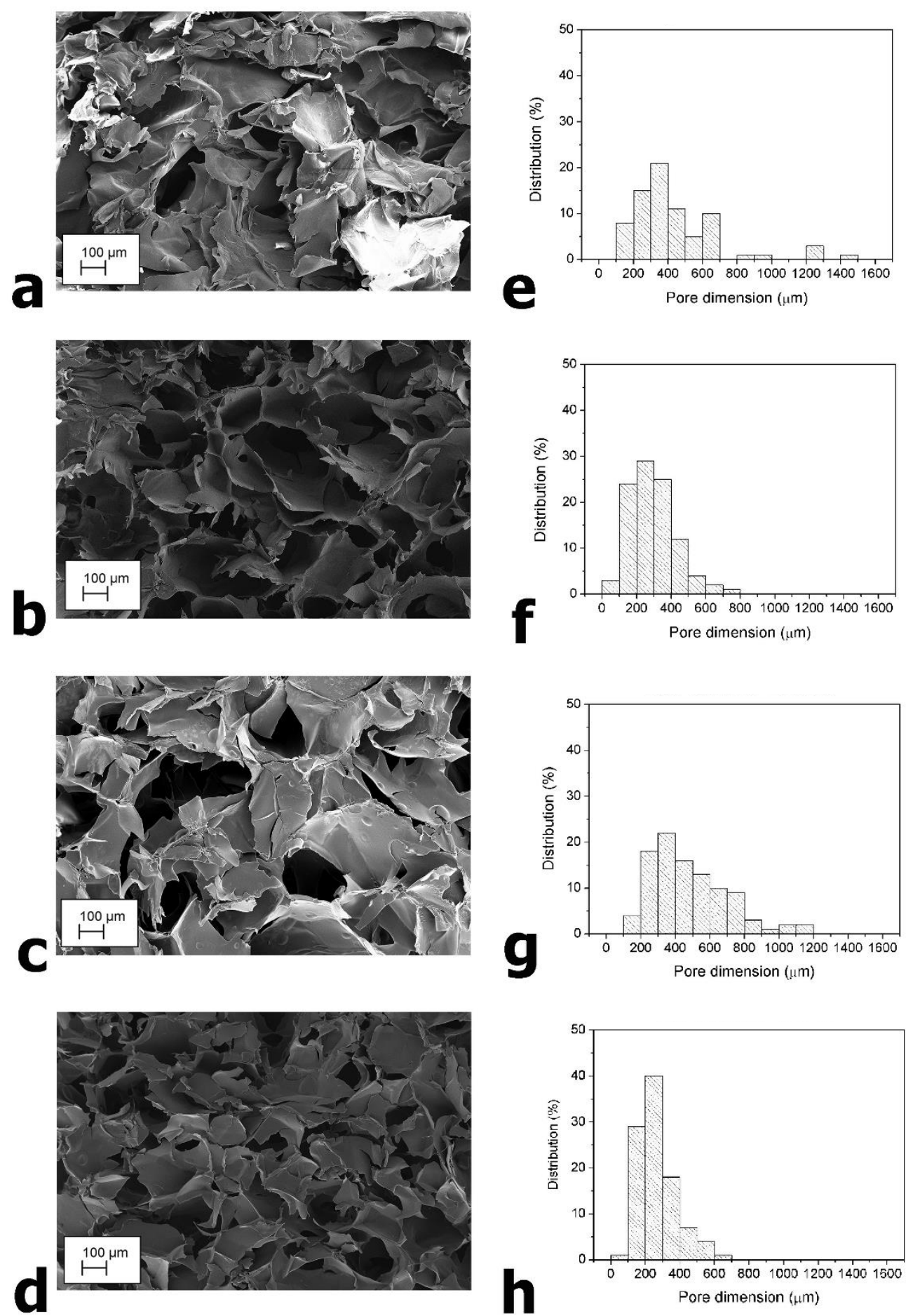

Figure 2 

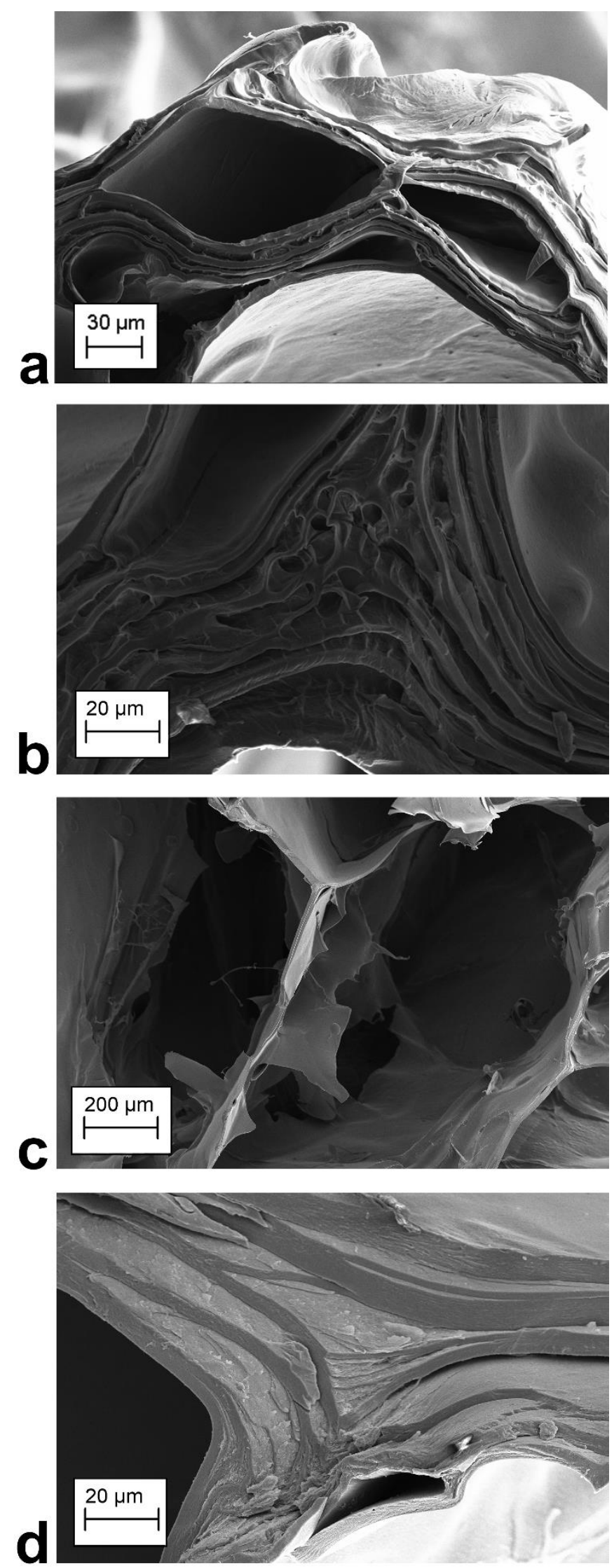

Figure 3 

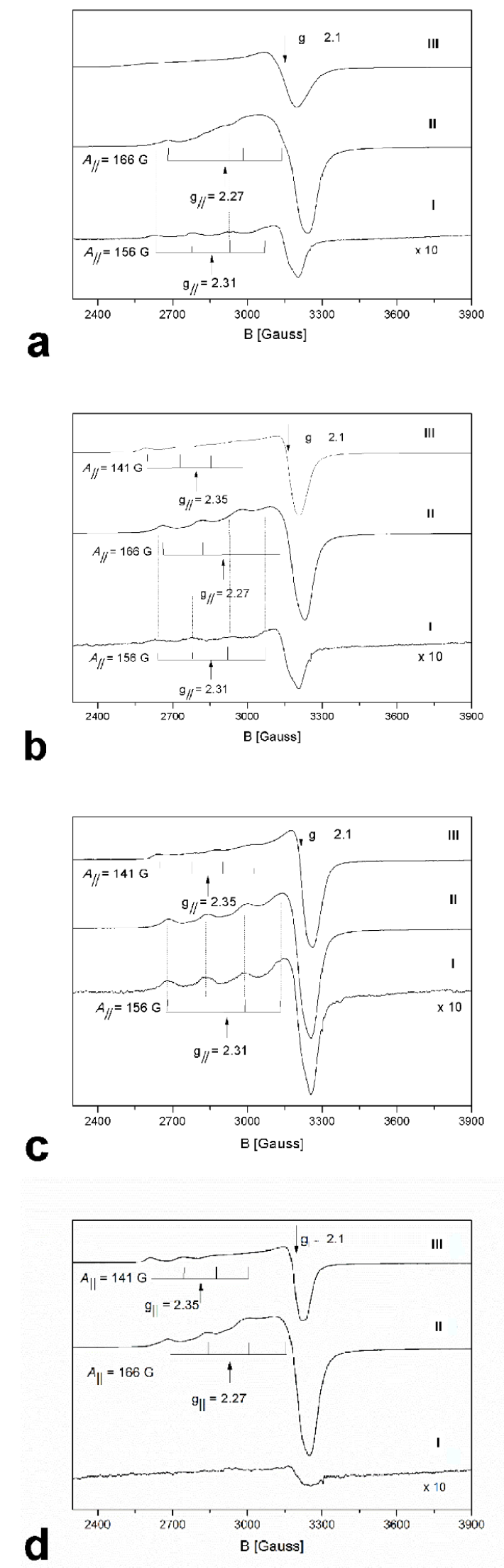

Figure 4 

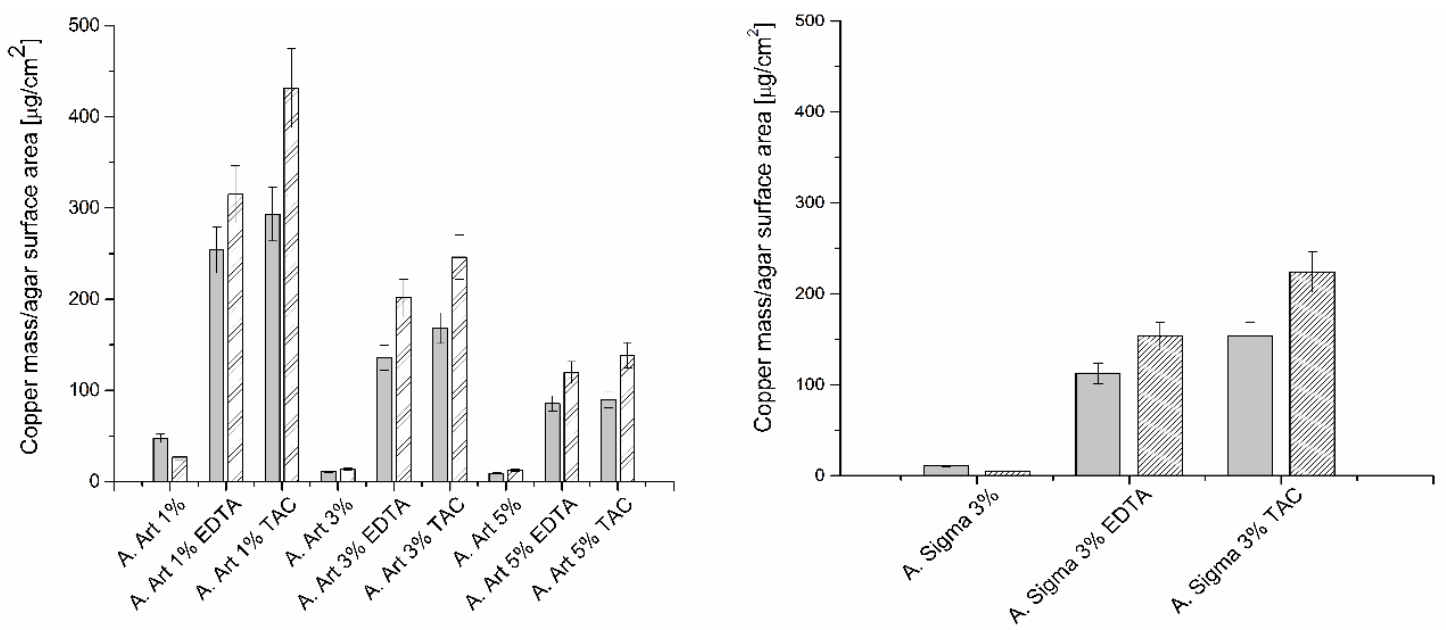

Figure 5 